\title{
RECEPÇÃO E ASSIMILAÇÃO DA CULTURA JAPONESA AFASTANDO-SE DO CAMINHO: A PERDA DOS PRINCÍPIOS "DÔ" PELOS DESCENDENTES DE IMIGRANTES JAPONESES
}

RESUMO: Tomando como base os princípios do "DÔ", do Bushido " Caminho do guerreiro", privilegiei como objeto de discussão para este encontro, argumentar os motivos que provocaram mudanças nos valores como o da honestidade e o da educação trazidos pelos imigrantes japoneses, bem como tentar justificar as causas do desinteresse ou não da língua e da cultura japonesa entre os descendentes de duas comunidades do Estado de São Paulo.

ABSTRACT: Considering the principles of the "DO" from Bushido "Way of the Warrior" I have chosen as the main object of discussion for this meeting the arguments that reveal the reasons for changes in values such as honesty and education originally brought by Japanese immigrants. I will also make an attempt in order to justify the interest and non-interest in the Japanese language and culture among decedents from two communities in the state of São Paulo.

Sem desconsiderar a importância dos fatores geográficos e políticos, tomarei como hipótese os princípios do "DO" (Caminho) para justificar o propósito do tema em si.

A perda gradativa desses princípios é, a meu ver, uma das razões pelas quais há uma falta de interesse dos descendentes japoneses pela continuidade dos ensinamentos de seus antepassados, seja no âmbito linguístico, seja no cultural.

Segundo Sakai (1979), para os imigrantes japoneses, "divulgar a cultura japonesa no Brasil é difundir e cultivar os pontos positivos do Japão e aqueles valores característicos do povo japonês tais como: a honestidade, a dedicação ao trabalho e o alto interesse pela educação" (Wawzyniak, 2008). Isso porque, para o imigrante japonês, essa difusão cultural era 
considerada um ponto de referência para a afirmação de seus valores culturais mantendo, com isso, as suas marcas de origem, na perspectiva de uma permanência temporária, pois, "se regressar ao Japão, levando estes filhos que não sabem ler nem falar japonês, teria que enfrentar o problema da comunicação entre pais e filhos e destes com parentes e amigos. E acima de tudo, seria uma vergonha para um súdito nipônico", segundo Mori (1992). Entretanto, embora a defesa desses valores na construção de uma imagem por parte dos próprios imigrantes possa parecer estereotipada suprimir, na realidade, está assentada em elementos acolhidos pelos próprios imigrantes a partir de seu núcleo cultural.

A cultura japonesa, embora seja altamente híbrida, pode-se dizer que tem seus pilares básicos oriundos do budismo e do confucionismo chineses transportados para o Japão Antigo. Não se pode esquecer, entretanto, que tais pilares estão fortemente impregnados pela filosofia taoísta, sobre cuja base se construiu inicialmente todo o edificio cultural chinês e, posteriormente, o japonês.

Nesse contexto, é bastante pertinente rastrear tais marcas nos elementos culturais comuns preservados pela primeira geração dos imigrantes que se fixaram no Brasil e que acabaram sendo transmitidos a seus descendentes.

Podemos dizer que essa ideia da fixação definitiva se deu, sobretudo, entre 1942 e 1952, em decorrência da Segunda Guerra Mundial, quando se interrompeu o movimento imigratório Japão Brasil. Foi o momento em que "a lealdade para com a pátria e o imperador estava mais voltada agora para o país adotivo, pátria dos filhos e netos; o plano inicial era substituído, quase que inconscientemente, pela permanência definitiva. Enfim, o sentido de existência havia mudado" (Saito, 1980).

A partir de então, os seus filhos, de acordo com as circunstâncias de seu ambiente, começaram a aprender ou somente a língua portuguesa ou ambas, a portuguesa e a japonesa.

$\mathrm{Na}$ visão dos imigrantes japoneses, a educação era o caminho para a ascensão social e um espaço em que os traços culturais japoneses poderiam ser difundidos. A escola em si, era um espaço sagrado.

Um traço marcante nos imigrantes japoneses era um sentimento de nacionalismo baseado nos preceitos do budismo combinado ao xintoísmo autóctone e ao confucionismo originário do Continente. Isto contribuiu para a formação de uma mentalidade nipônica com valores como o ( $K o$ ), devoção filial, sentimento de dever e gratidão aos pais e ancestrais, o (Chu), sentimento de fidelidade ao imperador e o (Gui), sentimento de Justiça, o de ser justo com todos, sem desigualdades.

Podemos observar a influência desses valores na psicologia do povo japonês na qual o respeito ao superior de forma humilde é produto desse sentimento do $K o$ e $C h u$, de gratidão e fidelidade. Além deles, também são constantes a exaltação da sensibilidade, 
pureza, honestidade, honra, nos quais o interesse próprio tem pouca importância, tal como ocorria com os Samurais, guerreiros que podiam chegar ao suicídio caso cometessem alguma desonra.

A lealdade dos japoneses talvez seja influenciada por esse sentimento de honra dos Samurais.

No Japão, o budismo vai atingir o seu auge principalmente a partir da Era Heian (794-1185), influenciando significativamente a cultura japonesa nas artes, na pintura, na literatura.

No tão discutido Bushido, o preceito da honra dos guerreiros será fortalecido com o surgimento do Zen, como uma das ramificações do budismo exotérico (ensinamento ao público); o Tendai ou Escola de Lótus, trazido da China pelo monge Saicho que propôs diversos meios de seguir o caminho búdico para atingir a iluminação.

Além do Zen, outra linha búdica existente nessa época, trazida também da China pelo monge Kukai, é o budismo esotérico (ensinamento no local mais restrito e fechado) o Shingon ou Escola dos Mistérios.

No Japão, o Zen marcou fortemente a vida espiritual e cotidiana do povo em geral. Com uma introdução mais significativa a partir do século XIII, Era Kamakura, influenciou todo o caminho dos guerreiros e seus adeptos com base na sua essência e nos seus princípios morais.

Por outro lado, as demais escolas budistas eram atraídas por outras castas sociais em que o Tendai atendia a família imperial, o Shingon, a nobreza e a Terra Pura, o povo (Handa, 1991).

Para Handa (1991), o Zen não propõe lutar contra a fatalidade, nem aceitá-la. Mas o agir (ou não agir) aqui e agora é importante no Zen. Foi este o principal gancho que os samurais resgataram do Zen para si. "Morrer" para o samurai era esquecer-se do ego o apego às coisas, inclusive a si mesmo. Ao "morrer" ele se libertava das paixões que o prendiam ao mundo das ilusões.

Podemos dizer que a nova fase da classe guerreira Zen em busca de um novo ideal, do verdadeiro objetivo do caminho guerreiro, decorreu em razão do fim do Período do País em Guerra que durara mais de 100 anos entre os daimyo (senhor feudal) para obter o controle do arquipélago.

Esse impasse foi decidido em 1600 na Batalha de Sekigahara, entre as duas faç̧ões que dividiam o Japão, o Exército do Leste, liderado por Itida Mitsunari e o clã de Osaka, e o Exército do Oeste, cujo chefe do clã de Edo, Tokugawa Ieyasu foi o vencedor, estabelecendo o regime Tokugawa (1603-1868) que duraria mais de 250 anos. 
O país, unificado pelo poder centralizado dos Tokugawa, passa a adotar uma política isolacionista, cortando o contato com o exterior.

Foi um período sem grandes rebeliões e batalhas, com muitos samurais enriquecendo com a ascendência de cargos burocráticos. Outros tornaram-se corruptos, esquecendo os princípios como honra, lealdade, coragem, gratidão, polidez, virtude e sinceridade valorizados pelo Bushido, Caminho do Guerreiro, o código de ética samurai.

Por outro lado, os samurais que lutaram junto à faç̧ão de Osaka, foram destituídos de seus senhores, pois foram extintos por ordem do xogum, tornando-se samurais errantes, ronins.

Segundo Kishikawa (2004), na década posterior a Sekigahara, muitos desses ronin passaram a frequentar ou até estabelecer escolas (dojo) para ensinar estilos específicos de artes marciais, surgindo, com isso, uma quantidade assustadora de estilos diversificados que se perderam com o tempo. Enquanto muitos dos ronin (samurais errantes) partiram para o lado da violência ou banditismo, outros ronin como Miyamoto Musashi, que lutou do lado do perdedor em Sekigahara isolavam-se para aperfeiçoar sua estratégia no manuseio da espada. Musashi venceu, posteriormente, mais de 30 duelos, sendo considerado o maior samurai de todos os tempos. Deixou o tratado no qual transmitiu seus conhecimentos sobre o uso da estratégia, o Livro dos Cinco Anéis, no qual destaca entre os seus ensinamentos que "quem domina um caminho, passa a vê-lo em todos os caminhos"

Para entender melhor a essência do Bushido, o vassalo do clã Nabeshima, Yamamoto Tsunetomo (1659-1719), que nasceu 60 anos após a batalha de Sekigahara, procurou honrar a tradição do samurai e defendeu valores elevados de coragem e disciplina que cada vez mais perdiam o sentido numa sociedade dominada pela burocracia e pela ganância.

Yamamoto Tsunetomo deixou também registros desses valores e princípios a serem respeitados pelos samurais no livro Hagakure, palavra que pode significar escondido pelas folhas ou folhas escondidas.

O declínio e a extinção oficial da classe samurai ocorreu quando o poder retornou às mãos do imperador Meiji.

Segundo Gonçalves (2004), o conceito de Caminho do Bushido é bem mais amplo do que o de Religião. O Caminho no Oriente (Marga em sânscrito, Tao em chinês, Michi ou $D o$ em japonês) engloba componentes religiosos, filosóficos, artísticos e até científicos. O caminho oriental é tudo isso. 
Lao Tsé, considerado o fundador do Taoísmo, nascido em 571 a.C. na província de Chu da China Antiga, nos diz em sua primeira proposição que o Tao (Caminho) que pode ser enunciado (tao) não é o Tao Perene. Em outras palavras: O Caminho que pode ser discorrido não é o Caminho Verdadeiro.

O Tao é apresentado como sendo a origem e dele emanam as forças yin e yang. Destas surge a tríade do Céu, Terra e Humanidade e, a partir dai, todas as formas de existência.

O Tao é o ensinamento da própria lei da natureza. Com a prática destes ensinamentos pode-se adquirir longevidade com saúde e chegar ao estado de iluminação e elevação espiritual. O taoísmo começou por atrair adeptos de todos os níveis da sociedade quase no fim da Era Han (206 a.C. a 220 a. C.). Rejeitando a todas as normas rígidas e os padrões aceitos, os taoístas proclamavam a virtude da individualidade e depreciavam todas as formas de compulsão, distorção e artificialidade. Prometiam a vida eterna não por meio dos esforços, mas do entendimento dos processos secretos da natureza.

Em outras palavras, tomando como base o ideograma do Tao (道) abaixo, o pequeno traço à esquerda ( ) da parte do ( 一 ) representa a energia Yin e o da direita ( ) representa a energia Yang. O traço (一) significa unir o Yin e Yang. O (自) originou-se do ( $)$ que representa o grande universo, sendo o traço horizontal superior o Yang ( céu ) e o inferior, o Yin ( terra). O (道) significa caminho. O pequeno traço acima do ( ) é o ( d ) grande universo. Assim, a Energia do grande universo Yin e Yang deve ser levada ao umbigo do corpo como ponto de partida para o Caminho da eternidade sem limites.

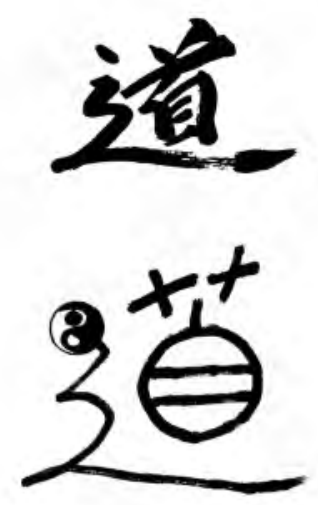

Em suma, praticar o Tao é estar em harmonia com a natureza, é ir ao encontro da união da natureza com o universo, que o taoísta se refere como União do Céu, Terra $\mathrm{e}$ Homem, como podemos exemplificar com o ideograma Jin a seguir, de compaixão, segundo os princípios do $D o$, caminho. 

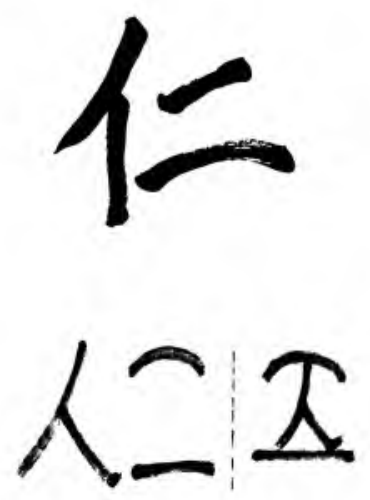

Do ponto de vista do Tao, o traço à esquerda é o ser humano ( 1 ) e os dois traços horizontais à sua direita (二 ), o Céu (traço superior) e a Terra (traço inferior). Aqui há o encontro do ser humano com a energia Yin e Yang do universo, atingindo o estágio do vazio, da serenidade, dando origem ao verdadeiro sentimento de compaixão, de solidariedade. $E$ é esse verdadeiro sentimento de gratidão ao seu mestre e ao próximo que deve ser passado como um dos princípios básicos da conduta de honra do Bushido.

No entanto, esta conduta parece ter se ou estar se distanciando entre as novas gerações, como por exemplo, entre os familiares de descendentes de japoneses.

Teria havido, nas gerações novas, um distanciamento dos valores da família e da relação com a natureza? Foi tal ruptura que marcou um afastamento com os elementos básicos da cultura japonesa tradicional e uma aproximação em relação à cultura brasileira?

Outra pergunta a ser feita seria se essa ruptura ocorreu apenas entre os imigrantes japoneses e seus descendentes ou é a marca da transição de uma sociedade agrária para uma sociedade industrializada.

Tomando como base os fundamentos da essência do "DÔ", Caminho, foco do meu questionamento, para tentar justificar essa ruptura presente, sobretudo, entre os da nova geração, apoiei-me, para coleta de dados, em alguns itens do questionário do corpus dos sujeitos das Três Alianças $\left(1^{\mathrm{a}}, 2^{\mathrm{a}}\right.$ e $\left.3^{\mathrm{a}}\right)$, localizada no interior de São Paulo, na cidade de Mirandópolis e da Vila Ipelândia/Fukuhaku Mura, da cidade de Suzano/ São Paulo. Pesquisa essa realizada como parte de um projeto conjunto de pesquisadores japoneses da Universidade de Osaka/Japão e de pesquisadores brasileiros das universidades de São Paulo, Federal do Rio de Janeiro e da Universidade de Campinas/ SP, denominada "Pesquisas sobre as Línguas Faladas nas Comunidades Nikkeis do Brasil", desenvolvida em 2003. 
Foram analisadas, por exemplo, questões referentes à aprendizagem da língua japonesa entre os informantes das duas comunidades entrevistadas, como estudo de caso, a Vila Ipelândia ou Fukuhaku Mura e Vila Aliança ( $1^{\mathrm{a}}, 2^{\mathrm{a}}$ e $3^{\mathrm{a}}$ Alianças) expressas por meio das perguntas a seguir:

Perg.1. Quando era criança, aprendeu a língua japonesa na escola?

\begin{tabular}{|c|c|c|c|c|c|}
\hline \multicolumn{3}{|c|}{ FUKUHAKU - MURA } & \multicolumn{3}{|c|}{ ALIANCA } \\
\hline \multirow{2}{*}{$\begin{array}{c}2^{2} \text { ger } \\
\text { ( } 41 \text { Inf. ) }\end{array}$} & Sim & 26 & \multirow{2}{*}{$\begin{array}{c}2^{\mathrm{a}} \text { ger } \\
\text { (42 Inf.) }\end{array}$} & Sim & 25 \\
\hline & Não & 15 & & Não & 17 \\
\hline \multirow{2}{*}{$\begin{array}{c}3^{\mathbf{a}} \text { ger. } \\
\text { ( } 28 \text { Inf. ). }\end{array}$} & Sim & 28 & \multirow{2}{*}{$\begin{array}{c}3^{\mathrm{a}} \text { ger. } \\
\text { ( } 28 \text { Inf.) }\end{array}$} & Sim & 28 \\
\hline & Não & --- & & Não & $\cdots$ \\
\hline
\end{tabular}

Perg.2. Quando era criança, conversava em qual língua?

\begin{tabular}{|c|r|r|r|}
\hline \multicolumn{2}{|c|}{ FUKUHAKU - MURA } & \multicolumn{2}{|c|}{ ALIANCA } \\
\hline & Jap: 17 & & Jap: 27 \\
& +Jap: 9 & +Jap: 7 \\
$\mathbf{2}^{\mathbf{a}}$ ger & Port + Jap: 6 & $\mathbf{2}^{\mathbf{a}}$ ger & Port + Jap: 5 \\
( 41 Inf. ) & +Port: 5 & (42 Inf.) & +Port: 2 \\
& Port: 4 & & Port: 1 \\
& Jap: 5 & & Jap: 2 \\
& +Jap: 1 & & +Jap: 4 \\
& Port + Jap: 8 & $\mathbf{3}^{\mathbf{a}}$ ger. & Port + Jap: 10 \\
( 28 Inf. ) & +Port: 9 & (28 Inf.) & +Port: 8 \\
& Port: 4 & & Port: 4 \\
\hline
\end{tabular}


Perg. 3 Acha necessário que os jovens aprendam a lingua japonesa?

\begin{tabular}{|c|c|c|c|c|c|}
\hline \multicolumn{3}{|c|}{ FUKUHAKU - MURA } & \multicolumn{3}{|c|}{ ALIANCA } \\
\hline \multirow{3}{*}{$\begin{array}{c}2^{\mathrm{a}} \text { ger } \\
\text { ( } 41 \text { Inf.). }\end{array}$} & Concordo & 25 & \multirow{2}{*}{$\begin{array}{c}2^{a} \text { ger } \\
\text { ( } 42 \text { Inf.) }\end{array}$} & Concordo & 32 \\
\hline & Não concordo & 4 & & Não concordo & 10 \\
\hline & Não sei & 12 & & Não sei & \\
\hline \multirow{3}{*}{$\begin{array}{c}3^{a} \text { ger. } \\
\text { ( } 28 \text { Inf.). }\end{array}$} & Concordo & 18 & \multirow{2}{*}{$\begin{array}{c}3^{a} \text { ger. } \\
\text { ( } 28 \text { Inf.) }\end{array}$} & Concordo & 16 \\
\hline & Não concordo & 1 & & Não concordo & 1 \\
\hline & Não sei & 9 & & Não sei & 11 \\
\hline
\end{tabular}

Perg.4 Sendo nikkei, acha óbvio saber falar em japonês?

\begin{tabular}{|c|c|c|c|c|c|}
\hline \multicolumn{3}{|c|}{ FUKUHAKU - MURA } & \multicolumn{3}{|c|}{ ALIANÇA } \\
\hline \multirow{3}{*}{$\begin{array}{c}2^{\mathrm{a}} \text { ger } \\
\text { ( } 41 \text { Inf. ). }\end{array}$} & Concordo & 28 & \multirow{2}{*}{$\begin{array}{c}2^{\mathrm{a}} \text { ger } \\
\text { ( } 42 \text { Inf.) }\end{array}$} & Concordo & 31 \\
\hline & Não concordo & 11 & & Não concordo & 7 \\
\hline & Não sei & 2 & & Não sei & 4 \\
\hline \multirow{3}{*}{$\begin{array}{c}3^{\mathrm{a}} \text { ger. } \\
\text { ( } 28 \text { Inf.). }\end{array}$} & Concordo & 14 & \multirow{2}{*}{$\begin{array}{c}3^{\text {a }} \text { ger. } \\
\text { ( } 28 \text { Inf.) }\end{array}$} & Concordo & 15 \\
\hline & Não concordo & 11 & & Não concordo & 9 \\
\hline & Não sei & 2 & & Não sei & 4 \\
\hline
\end{tabular}

Os dados mostram que, apesar dos japoneses, em específico da Aliança e Fukuhaku Mura, estarem deixando de lado a língua japonesa, de forma contraditória eles acham importante a aprendizagem e o uso da língua. No caso dos descendentes da $3^{a}$ geração dessas duas comunidades, não estariam eles se desprendendo da natureza, da essência do $D o$, em direção ao caminho do individualismo? Isso marcaria a ruptura com a ideia coletividade (tanto ocidental [solidariedade] quanto oriental), e levaria ao abandono dos valores tradicionais.

O afastamento do "DÔ" (Caminho) é algo específico da terceira geração de descendentes japoneses ou é um fenômeno mais universal decorrente da globalização e, consequentemente, da perda de valores tradicionais e culturais? A própria cultura japonesa no Japão estaria sendo atingida por este fenômeno? 
Bibliografia

BATH, Sérgio. Japão: ontem e hoje. São Paulo: Ática, 1993.

BENEDICT, Ruth. O Crisântemo e a Espada. Tradução: Cézar Tozzi. São Paulo: Perspectiva, 2002.

BAREAU, André. Budismo e Cristianismo. Petrópolis: Vozes, 1970.

GONÇALVES, M. R. CENTRO DE CHADO URASENKE DO BRASIL. DO: A Essência da Cultura Japonesa. São Paulo: Centro de Chado Urasenke do Brasil, 2004.

HANDA, Francisco. O que é Zen. São Paulo: Brasiliense, 1991.

HANDA, T. Destino da língua japonesa no Brasil. In: SAITO, M. \& MAYEMA, T. (orgs.)

Assimilação e integração dos japoneses no Brasil. Petrópolis: Vozes; São Paulo: EDUSP, 1993.

O Imigrante Japonês: História de sua Vida no Brasil. São Paulo: T.A. Queiroz e Centro de Estudos Nipo-Brasileiros, 1987.

HAMMITZSCH, Horst. O Zen na Arte da Cerimonia do Chá. Tradução: Alayde Mutzenbecher. 10. Ed. São Paulo: Pensamento, 1997.

HERRIGEL, Eugen. O Caminho do Zen . 9. Ed. São Paulo: Pensamento, 1993.

IKEDA, Daisaku. Budismo: O Primeiro Milênio. São Paulo: Record, 1977.

KISHIKAWA, Jorge. Shinhagakure-pensamento de um samurai moderno. São Paulo:

Conrad Editora do Brasil Ltda, 2004.

KUNIYOSHI, Celina. Imagens do Japão- uma utopia de viajantes. São Paulo: Estação Liberdade, 1998.

MIYAO, Sussumu. Nipo-Brasileiros - processo de assimilação. Trad. KATSUNORI Wakisaka. São Paulo: Centro de Estudos Nipo-Brasileiros, 2002.

NORMAND, Henry. Os Mestres do Tao. Tradução: Maria Stela Gonçalves. 9.ed. São Paulo: Pensamento, 1993.

OSAKA UNIVERSITY. Memoirs of the Graduate School of Letters Osaka University. Japão: Osaka University, Vol 44, 2004.

PALMER, Martin. Elementos do Taoísmo. Tradução: Cláudia Gerpe Duarte. São Paulo: Ediouro, 1993.

SAITO, H. A presença Japonesa no Brasil. In: Participação, mobilidade e identidade. São Paulo: EDUSP, 1980.

SHIODA, Kenichi. Chi Kong Pai Lin e Quiropraxia com Energização. São Paulo: Paulo's Comunicação e Artes Gráfica Ltda, 2007. 
MORI, K. et al. In: Uma Epopéia Moderna - 80 anos da Imigração Japonesa no Brasil.

São Paulo: Hucitec/ Sociedade Brasileira de Cultura Japonesa, 1992.

SUZUKI, Daisetsu. Kami to Nihon Bunka. 6.ed., Japão: Iwanami Shinsho, 1997.

SUZUKI, Takeshi. Budismo: Do primitivo ao Japonês São Paulo: Editora do Escritor;

Luz e Silva Editor, 1985.

LAO, Tsé. Tao Te King: O Livro do Sentido e da Vida. São Paulo: Hemus, s/d.

SUN, Tzu et alli. Sábios Guerreiros. São Paulo: Claridade, 2004.

Wawzyniak, S. Maria. A "colônia" como representação: imigração japonesa no Brasil. In:

Cem anos da imigração japonesa. São Paulo: Editora Edunesp, 2008.

WILSON, Willian Scott ( Organizador). Hagakure-o livro do samurai. São Paulo: Conrad Editora do Brasil Ltda, $3^{a}$ ed., 2005. 